\title{
Effects of antibiotic consumption on children 2-8 years of age developing asthma
}

\author{
Hamid Reza Khalkhali ${ }^{1,2}$, Sima Oshnouei ${ }^{3}$, Shaker Salarilak ${ }^{4}$, Mohammadhossein Rahimi Rad $^{5}$, \\ Mohammad Karamyar ${ }^{6}$, Javad Khashabi ${ }^{7}$ \\ ${ }^{1}$ Inpatient Safety Research Center, Faculty of Medicine, Urmia University of Medical Sciences, Urmia; ${ }^{2}$ Department of Biostatistics and \\ Epidemiology, Faculty of Medicine, Urmia University of Medical Sciences, Urmia; ${ }^{3}$ Reproductive Health Research Center, Urmia University of \\ Medical Sciences, Urmia; “ Department of Public Health, Faculty of Medicine, Tabriz Branch, Islamic Azad University, Tabriz; ${ }^{5}$ Department of \\ Respiratory Medicine, Faculty of Medicine, Urmia University of Medical Sciences, Urmia; ${ }^{6}$ Department of Pediatrics, Motahari Hospital, Faculty \\ of Medicine, Urmia University of Medical Sciences, Urmia; ${ }^{7}$ Department of Pediatrics, Faculty of Medicine, Urmia University of Medical \\ Sciences, Urmia, Iran
}

OBJECTIVES: Antibiotic exposure in children is a possible contributor to the increasing asthma prevalence in several countries. The present study aimed to investigate the association between antibiotic exposure and the risk of developing childhood asthma at 2-8 years of age.

METHODS: A case-control study was undertaken among children aged 2-8 years old between March and September 2010 in the Urmia district in the northwest of Iran. The cases were doctor-diagnosed asthmatic children based on Global Initiative for Asthma criteria $(n=207)$, and the controls were children without respiratory symptoms $(n=400)$ selected by frequency matching by age and gender. Clinical data including antibiotic exposure was collected by a validated and reliable questionnaire, which was completed by interviewing parents/guardians.

RESULTS: Antibiotic consumption during the first year of life increased the odds ratio [OR] of asthma symptoms at 2-8 years of age (crude OR, 2.26; 95\% confidence interval [CI], 1.53-3.35; $\mathrm{p}<0.01$ ), and the strength of association was similar after adjusting for a family history of asthma or atopic disorder, preterm delivery, birth order, and delivery method (adjusted OR, 1.91; 95\% CI, 1.27-2.88; $\mathrm{p}=0.03$ ).

CONCLUSIONS: Our study suggests that antibiotic consumption in children was associated with an increased risk of childhood asthma, and an additional confirmative study is needed.

KEY WORDS: Antibiotic use, Childhood asthma, Case-control studies

\section{INTRODUCTION}

Asthma is the most common chronic disease in childhood, affecting up to 300 million people in the world [1]. During the

\footnotetext{
Correspondence: Shaker Salarilak

Department of Public Health, Faculty of Medicine, Tabriz Branch, Islamic Azad University, Manzaryeh square, Solyman Street, Tabriz 51747-43196, Iran Tel: +98-4412240461, Fax: +98-4412240641, E-mail: salari@iaut.ac.ir Received: Jan 28, 2013, Accepted: May 7, 2014, Published: Jul 4, 2014 This article is available from: http://e-epih.org/

(C) 2014, Korean Society of Epidemiology

(C) This is an open-access article distributed under the terms of the Creative Commons Attribution License (http://creativecommons.org/licenses/by/3.0/), which permits unrestricted use, distribution, and reproduction in any medium, provided the original work is properly cited.
}

last decades, many lifestyle behaviors including, dietary patterns, and health behaviors related with life style have changed the pattern of asthma and other respiratory disorders across the world, particularly in developing countries [2].

Antibiotics are broadly used to treat various infections in childhood. A great deal of evidence suggests that gastrointestinal flora plays a prominent role in developing a healthy immune system and resistance to allergic sensitization [3]. Newer studies have shown that antibiotic consumption in early life may increase the development of asthma by reducing the protective effect of bacterial infections and disturbance of the normal gut bacterial flora $[4,5]$. but no significant association between antibiotic exposure and developing asthma and other allergic disorders in childhood has been identified [6]. Neverthe- 
less, decreasing excess antibiotic consumption in childhood is recommended [7].

This article reports on data drawn from a observational study investigating potential risk factors for the development of childhood asthma in subjects 2-8 years of age in the city of Urmia, in the northwest of Iran, and the primary objective was to investigate the association between antibiotic exposure and the risk of developing childhood asthma.

\section{MATERIALSAND METHODS}

This investigation was a case-control study conducted between March and September 2010 in Urmia, Iran.

The study was approved by the Human Research Ethics Committee of Urmia University of Medical Sciences, and the questionnaire was administered by the author after verbal consent was obtained from all of the participating children's parents.

The cases $(n=207)$ were selected from among children 2-8 years of age who were referred to the Motahhari Children's Polyclinic and the Asthma and Allergy Pediatric Center. To re- cruit incident asthmatic patients, we adopted the Global Initiative for Asthma (GINA) criteria prospectively between March and September 2010. The patient's history of lower respiratory infections was assessed in the questionnaire in order to reduce the likelihood of reverse causation and reduce the likelihood of needing a differential diagnosis between asthma and respiratory tract infections, all of the patients with a history of severe respiratory infections during the first two years of life were excluded from the study population.

Controls $(n=400)$ were selected from among children of the same age range whose parents did not report any history of asthma or allergic disorders. To reduce selection bias, we selected controls from hospitalized and healthy children who visited the Motahhari Children's Polyclinic, matched by age and gender using the frequency matching method:The hospitalized controls were selected from among the patients without any allergic or respiratory disease, and the healthy controls were selected from among the children that were referred to the health centers for their routine growth monitoring. Additional controls were recruited from areas of the city in which the cases were

Table 1. Distribution of demographic and other features in the study population

\begin{tabular}{|c|c|c|c|c|c|}
\hline Variables & & Cases & Healthy controls & Hospitalized controls & p-value ${ }^{1}$ \\
\hline Antibiotic use during the first year of life & $\begin{array}{l}\text { No } \\
\text { Yes }\end{array}$ & $\begin{array}{r}47(28.1) \\
120(71.9)\end{array}$ & $\begin{array}{r}84(43.3) \\
110(56.7)\end{array}$ & $\begin{array}{l}98(50.8) \\
95(49.2)\end{array}$ & $<0.01$ \\
\hline Exposure to antibiotics during pregnancy & $\begin{array}{l}\text { No } \\
\text { Yes }\end{array}$ & $\begin{array}{r}145(76.3) \\
45(23.7)\end{array}$ & $\begin{array}{r}130(75.1) \\
43(14.9)\end{array}$ & $\begin{array}{r}155(79.5) \\
40(20.5)\end{array}$ & 0.57 \\
\hline Sex & $\begin{array}{l}\text { Male } \\
\text { Female }\end{array}$ & $\begin{array}{r}121(58.1) \\
85(41.3)\end{array}$ & $\begin{array}{r}113(56.5) \\
87(43.5)\end{array}$ & $\begin{array}{r}115(57.5) \\
85(41.3)\end{array}$ & 0.91 \\
\hline Living area & $\begin{array}{l}\text { Urban } \\
\text { Rural }\end{array}$ & $\begin{array}{c}195(95.6) \\
9(4.4)\end{array}$ & $\begin{array}{r}179(89.9) \\
20(10.1)\end{array}$ & $\begin{array}{c}181(91.0) \\
18(9.0)\end{array}$ & 0.08 \\
\hline Age at time of diagnosis (yr) & $\begin{array}{l}2-4 \\
4-6 \\
6-8\end{array}$ & $\begin{array}{l}230(38.4) \\
208(34.7) \\
161(26.9)\end{array}$ & & & \\
\hline History of passive smoking (yr) & $\begin{array}{l}\text { Never } \\
<10 \\
11-19 \\
\geq 20\end{array}$ & $\begin{array}{c}147(71.0) \\
34(16.4) \\
5(2.4) \\
21(10.2)\end{array}$ & $\begin{array}{c}150(75.0) \\
30(15.0) \\
4(180.0) \\
16(8.2)\end{array}$ & $\begin{array}{c}140(70.0) \\
32(16.0) \\
4(1.9) \\
24(12.1)\end{array}$ & 0.89 \\
\hline Birth order & $\begin{array}{l}1-2 \\
\geq 3\end{array}$ & $\begin{array}{c}191(95.5) \\
16(4.5)\end{array}$ & $\begin{array}{r}179(89.5) \\
20(10.5)\end{array}$ & $\begin{array}{r}163(81.5) \\
37(18.5)\end{array}$ & $<0.01$ \\
\hline Birth weight (g) & $\begin{array}{l}<2,500 \\
\geq 2,500\end{array}$ & $\begin{array}{c}15(7.6) \\
182(92.4)\end{array}$ & $\begin{array}{c}10(5.2) \\
183(94.8)\end{array}$ & $\begin{array}{c}10(5.2) \\
183(94.8)\end{array}$ & 0.51 \\
\hline Delivery method & $\begin{array}{l}\text { Vaginal } \\
\text { Caesarean }\end{array}$ & $\begin{array}{r}84(40.6) \\
123(59.4)\end{array}$ & $\begin{array}{r}91(45.7) \\
108(54.3)\end{array}$ & $\begin{array}{r}116(58.0) \\
84(42.0)\end{array}$ & $<0.01$ \\
\hline Preterm delivery ( $\leq 37 w k$ ) & $\begin{array}{l}\text { No } \\
\text { Yes }\end{array}$ & $\begin{array}{r}174(84.5) \\
32(15.5)\end{array}$ & $\begin{array}{r}178(89.4) \\
21(10.6)\end{array}$ & $\begin{array}{c}189(94.5) \\
11(5.5)\end{array}$ & $<0.01$ \\
\hline History of mother smoking & $\begin{array}{l}\text { No } \\
\text { Yes }\end{array}$ & $\begin{array}{c}203(99.5) \\
1(0.5)\end{array}$ & $\begin{array}{c}197(98.5) \\
3(1.5)\end{array}$ & $\begin{array}{c}198(99.0) \\
0(0)\end{array}$ & 0.54 \\
\hline $\begin{array}{l}\text { History of asthma or atopic disorders in the } \\
\text { first or second degree relatives }\end{array}$ & $\begin{array}{l}\text { None } \\
\text { Asthma } \\
\text { Atopic disorders } \\
\text { Both }\end{array}$ & $\begin{array}{l}52(25.5) \\
44(21.6) \\
78(38.2) \\
30(14.7)\end{array}$ & $\begin{array}{l}86(43.2) \\
30(15.1) \\
64(32.2) \\
19(9.5)\end{array}$ & $\begin{array}{l}119(59.5) \\
15(7.5) \\
58(29) \\
8(4)\end{array}$ & $<0.01$ \\
\hline
\end{tabular}

Values are presented as number (\%).

${ }^{1}$ Chi squared or Fisher's exact test. 
Table 2. Distribution of antibiotic consumption and other risk factors during the first year of life and risk of asthma at 2-8 years

\begin{tabular}{|c|c|c|c|c|}
\hline Variables & Crude OR $(95 \% \mathrm{Cl})$ & p-value ${ }^{1}$ & Adjusted OR (95\% Cl) & p-value ${ }^{1}$ \\
\hline \multicolumn{5}{|c|}{ Antibiotic use during the first year of life } \\
\hline $\begin{array}{l}\text { No } \\
\text { Yes }\end{array}$ & $\begin{array}{c}1.00 \\
2.26(1.53-3.35)\end{array}$ & $<0.01$ & $\begin{array}{c}1.00 \\
1.91(1.27-2.88)\end{array}$ & $<0.05$ \\
\hline \multicolumn{5}{|l|}{ Adjusted variables } \\
\hline \multicolumn{5}{|c|}{ History of asthma or atopic disorders in the first- or second-degree relatives } \\
\hline None & 1.00 & $<0.01$ & 1.00 & $<0.01$ \\
\hline Asthma & $3.85(2.30-6.45)$ & & $3.36(1.83-5.81)$ & \\
\hline Atopic disorders & $2.52(1.66-3.82)$ & & $2.65(1.67-4.20)$ & \\
\hline Asthma/atopic disorders & $4.38(2.39-8.00)$ & & $4.43(2.31-8.49)$ & \\
\hline \multicolumn{5}{|l|}{ Preterm delivery ( $\leq 37 w k)$} \\
\hline No & 1.00 & $<0.01$ & 1.00 & $<0.01$ \\
\hline Yes & $2.10(1.25-3.55)$ & & $2.21(1.23-3.99)$ & \\
\hline \multicolumn{5}{|l|}{ Birth order } \\
\hline $1-2$ & 1.00 & 0.01 & NA & \\
\hline$\geq 3$ & $0.7(0.52-0.94)$ & & & \\
\hline \multicolumn{5}{|l|}{ Delivery method } \\
\hline Vaginal & 1.00 & $<0.01$ & NA & \\
\hline Caesarean & $1.57(1.12-2.21)$ & & & \\
\hline
\end{tabular}

OR, odds ratio; $\mathrm{Cl}$, confidence interval; NA, not applicable.

${ }^{1} \mathrm{p}$-value in the univariate regression model.

living to reduce socioeconomic differences and other unknown confounding factors between cases and controls.

A validated questionnaire prepared by the International Study of Asthma and Allergies in Childhood (ISSAC, Phase III) was used for data collection. It was translated into the Persian language first, and data related to the history of antibiotic consumption in the first year of life and during pregnancy were collected by interviewing the parents/guardians.

All of the questionnaires were completed by one interviewer in order to enhance the reliability of the results.

Because all of the risk factors in the childhood asthma-based ISSAC hypotheses were evaluated in this study, we used procedures to identify factors related to childhood asthma.

The Pearson chi-squared test was applied to assess the association between antibiotic exposure and risk of childhood asthma. We fitted multiple logistic regression models using a stepwise selection strategy with statistically significant variables that were reported as confounding factors in previous studies including maternal smoking, history of asthma or atopic disease in the first- and second-degree relatives, duration of breastfeeding, number of older/younger siblings in the household, preterm delivery, and delivery method [8,9]. STATA version 10.0 (StataCorp, College Station, TX, USA) was used for data analysis.

\section{RESULTS}

Antibiotics were used by 45 cases $(23.7 \%), 43$ healthy controls $(14.9 \%)$, and $40(20.5 \%)$ hospitalized control mothers of patients. Maternal antibiotic consumption during pregnancy had no significant effects on the risk of developing asthma in the study population; therefore, it was not entered in the regression model (crude odds ratio [OR], 1.20; 95\% confidence interval [CI], 0.76-0.84; $\mathrm{p}=0.42$ ).

Antibiotics were used by 120 cases $(71.9 \%)$ and 205 controls (56.7 and $49.2 \%$ of hospitalized and healthy controls, respectively) during the first year of life, and this had a significant effect on the risk of asthma $(p<0.01)$. All of mothers was not report history of smoking during pregnancy (Table 1 ).

Table 2 shows crude and adjusted odds ratios for the association of antibiotic consumption and other important risk factors during the first year of life and the risk of asthma in children 2-8 years of age. Interactions between antibiotic consumption and other asthma risk factors were not statistically significant and were thus removed in a stepwise selection method ( $p>0.05)$. Antibiotic consumption during the first year of life increased the risk of asthma symptoms at 2-8 years of age (crude OR, 2.26; 95\% CI, 1.50-3.35; $\mathrm{p}<0.01$ and adjusted OR, 1.91; 95\% CI, 1.27-2.88; $\mathrm{p}<0.05)$.

\section{DISCUSSION}

Antibiotic exposure during the first year of life significantly increased the risk of asthma at 2-8 years of age. Even though antibiotic exposure during fetal development was higher among the cases than the control groups (23.7\% of cases vs. $22.6 \%$ of controls), the difference was not statistically significant $(p=0.57)$.

Although our study design has the same limitations of other case-control studies, we tried to reduce interviewer bias by having a single trained nurse conduct all interviews. The standard GINA criteria were used to avoid the common 
differential in childhood asthma. Antibiotic consumption during the first year of life increased odds of asthma at 2-8 years, and this association was persistent even after adjusting for significant risk factors in the multiple regressions.

Our antibiotic hypotheses were based on Wickens' study, which showed an associated risk of asthma, allergic rhino-conjunctivitis, and atopic eczema in patients who were administered antibiotics in early childhood [10]. ISSAC Phase III has investigated many factors that have been hypothesized to increase the risk of asthma and other allergic disorders in childhood. That study investigated the effect of antibiotic consumption and the subsequent increased risk of these allergic disorders in 193, 412 children from 71 centers in 29 countries using cross-sectional surveys. Although it was found that acetaminophen use was associated with an increased risk of asthma and other allergic disorders, the same data set yielded a much stronger association for antibiotics compared to acetaminophen exposure [11].

A recent review study by Murk and colleagues has suggested two probable confounders for such relationships: "reverse causality" and "protopathic bias" [12]. A significant association has also been reported between antibiotic consumption and increased risk of childhood asthma through a prospective study and a sensitivity analysis has also been performed to evaluate protopathic bias [13,14], Kozyrskyj et al. [15] have shown this association using a cohort study of 13,116 children (OR, 1.86; $95 \% \mathrm{CI}, 1.02-3.37)$, in which the risk of asthma was stronger in children who had received more courses of antibiotics (OR,1.46; $95 \%$ CI, 1.14-1.88). Risnes and colleagues have concluded that antibiotic consumption increased the risk of developing childhood asthma even in children not having experienced respiratory tract infections and in children whose disease was diagnosed after 3 years of age and all cases whose disease was diagnosed before 2 years of age were excluded from the case group to reduce the risk of protopathic bias well as the risk of reverse causation [14].

In conclusion, we found the odds of childhood asthma to be associated with antibiotic use in children. We recommend a further prospective cohort studies on the association between antibiotic use in early life and childhood asthma.

\section{ACKNOWLEDGEMENTS}

This article and its results were extracted from thesis of Oshnouei S, Master of Epidemiology, and the study was conducted in Urmia University of Medical Sciences. This study was funded by the Research Deputy of Urmia University of Medical Sciences. We thank our colleagues at the Motaharri Pediatric Center, health professionals in the Urmia health centers; and all the centers and children who participated. We also thank Dr. Khashabi and her secretary for helping to identify study patients.

\section{CONFLICT OF INTEREST}

The authors have no conflicts of interest to declare for this study.

\section{REFERENCES}

1. World Health Organization. Global surveillance, prevention and control of chronic respiratory diseases: a comprehensive approach. Geneva: World Health Organization; 2007, p. 65.

2. Beasley R, Crane J, Lai CK, Pearce N. Prevalence and etiology of asthma. J Allergy Clin Immunol 2000;105:S466-S472.

3. Holt PG, van den Biggelaar AH. 99th Dahlem conference on infection, inflammation and chronic inflammatory disorders: the role of infections in allergy: atopic asthma as a paradigm. Clin Exp Immunol 2010;160: 22-26.

4. Mendall MA, Kumar D. Antibiotic use, childhood affluence and irritable bowel syndrome (IBS). Eur J Gastroenterol Hepatol 1998;10: 59-62.

5. Farooqi IS, Hopkin JM. Early childhood infection and atopic disorder. Thorax 1998;53:927-932.

6. Foliaki S, Nielsen SK, Björkstén B, Von Mutius E, Cheng S, Pearce $\mathrm{N}$, et al. Antibiotic sales and the prevalence of symptoms of asthma, rhinitis, and eczema: The International Study of Asthma and Allergies in Childhood (ISAAC). Int J Epidemiol 2004;33:558-563.

7. Nyquist AC, Gonzales R, Steiner JF, Sande MA. Antibiotic prescribing for children with colds, upper respiratory tract infections, and bronchitis. JAMA 1998;279:875-877.

8. Droste JH, Wieringa MH, Weyler JJ, Nelen VJ, Vermeire PA, Van Bever HP. Does the use of antibiotics in early childhood increase the risk of asthma and allergic disease? Clin Exp Allergy 2000;30:15471553.

9. Marra F, Marra CA, Richardson K, Lynd LD, Kozyrskyj A, Patrick $\mathrm{DM}$, et al. Antibiotic use in children is associated with increased risk of asthma. Pediatrics 2009;123:1003-1010.

10. Wickens K, Pearce N, Crane J, Beasley R. Antibiotic use in early childhood and the development of asthma. Clin Exp Allergy 1999;29:766771.

11. Foliaki S, Pearce N, Björkstén B, Mallol J, Montefort S, von Mutius E, et al. Antibiotic use in infancy and symptoms of asthma, rhinoconjunctivitis, and eczema in children 6 and 7 years old: International Study of Asthma and Allergies in Childhood Phase III. J Allergy Clin Immunol 2009; 124:982-989.

12. Murk W, Risnes KR, Bracken MB. Prenatal or early-life exposure to antibiotics and risk of childhood asthma: a systematic review. Pediatrics 2011;127:1125-1138.

13. Martel MJ, Rey E, Malo JL, Perreault S, Beauchesne MF, Forget A, et al. Determinants of the incidence of childhood asthma: a two-stage case-control study. Am J Epidemiol 2009;169:195-205.

14. Risnes KR, Belanger K, Murk W, Bracken MB. Antibiotic exposure by 6 months and asthma and allergy at 6 years: Findings in a cohort of 1,401 US children. Am J Epidemiol 2011;173:310-318.

15. Kozyrskyj AL, Ernst P, Becker AB. Increased risk of childhood asthma from antibiotic use in early life. Chest 2007;131:1753-1759. 